\title{
NUMERICAL EXPERIMENTS OF THE STRUCTURES OF ATMOSPHERIC ELECTRICAL ELEMENTS DURING A SNOWFALL NEAR A BUILDING
}

\author{
Y. Asuma and K. Kikuchi \\ Department of Geophysics, Faculty of Science, Hokkaido University, \\ Sapporo 060, Japan
}

\begin{abstract}
Atmospheric electrical elements during a snowfall near a building were examined by means of two dimensional numerical experiments which took into account a cylindrical building $10 \mathrm{~m}$ in radius and $22 \mathrm{~m}$ in height. Wilson's selective ion capture process and the supplement of ions due to the corona discharge from the ground surface are considered in these experiments. As the electric field on the roof of the building is intensified, a corona discharge is liable to occur there and a large number of ions are emitted from the roof into the atmosphere. Although the ions move upward owing to the electric force, they cannot reach higher altitude and a high concentration of ions appear below a $40 \mathrm{~m}$ level. On the other hand, snow particles are rapidly electrified below the $60 \mathrm{~m}$ level. Therefore, ions emitted from the roof of the building are captured by snow particles and the charges on snow particles are released to the ground surface. These calculated results qualitatively agree with the observation results described in a previous paper (Asuma et al., 1988).
\end{abstract}

\section{Introduction}

The mirror image relation is one of the fundamental problems in the atmospheric electricity. That is to say, the charge on individual precipitation particles has an opposite sign to that of atmospheric electric potential gradient. This relation is always held during snowfalls under the condition of relatively quiet and sinusoidal variation of the electric potential gradient. Observational surveys and analyses concerned with this relation have been reported by Chalmers (1951), Smith (1955), Ogawa (1960), Magono and Orikasa (1966), Kikuchi (1975), Kikuchi et al. (1979) and so on.

Asuma et al. (1988) examined this relation by means of tethered balloon observations during snowfalls and they obtained the following results; 1) The mirror image relation is always observed near the ground surface but it becomes somewhat obscure at $100 \mathrm{~m}$ or $200 \mathrm{~m}$ aloft. 2) The charge on individual snow particles is small aloft and large near the ground surface. 3) Comparing the records observed on the ground surface with those on the roof of a neighboring building, it is clear that the electric potential gradient is distorted by ions emitted by the corona discharge and the precipitation particles are mostly electrified on the ground.

From these results, they suggested that the most probable electrification mechanism for the mirror image relation is Wilson's selective ion capture process. These observational results can be interpreted that the atmospheric electrical elements are strongly affected by the phenomena near the ground surface. In this paper, the behavior of atmospheric electrical elements near a building will be discussed by means of a two dimensional numerical experiment.

2. Outline of calculations

These numerical experiments are based on Asuma and Kikuchi's numerical experiments (1987). Adopting the cylindrical coordinate and assuming the 
cylindrical building ( $10 \mathrm{~m}$ in radius and $22 \mathrm{~m}$ in height), the structures of several atmospheric electrical elements near the building were investigated.

\section{2-1. Precipitation particles}

The numerical experiments were carried out in the case of snowfalls. Type and intensity of the snowfalls are assumed to be snowflakes of $2 \mathrm{~mm} \cdot \mathrm{h}^{-1}$ and the intensity is constant throughout the period of experiments. As to the size distribution of the snowflakes, we adopt the relation between the number density of snowflakes and the melting diameter which proposed by Gunn and Marshall (1958). As suggested by Asuma and Kikuchi (1983), a snowflake acquires the charge proportional to its cross section area. Therefore, the relation between the melting diameter and maximum dimension of snowflakes is referred to as the relation of "Aggregates of densely rimed radiating assemblages of dendrites or dendrites" (Locatelli and Hobbs, 1974). Gunn and Marshall's relation (1958) is used for the fall speed of snowilakes. The size distribution of snowflakes used in the experiments is linearly divided into 12 classes based on their diameters (maximum dimensions) from 0 to $24 \mathrm{~mm}$.

2-2. Electrification on precipitation particles

The time variation of the charge on a snowflake is given by

$$
\frac{\partial}{\partial t^{2}} Q_{i}=v_{i} \frac{\partial}{\partial z} Q_{i}+\frac{\delta}{\delta t^{2}} Q_{i}+\nabla\left(K \nabla Q_{i}\right),
$$

where $Q_{i}$ and $V_{i}$ are the charge and fall speed on $i$ 'th classified snow particle, respectively. $\mathrm{K}$ is the eddy diffusion coefficient of precipitation charges. The first term in the right hand side of $\mathrm{Eq}$. (I) is the advection term. The fall speed is assumed to be constant and the flow due to winds is not taken into account. The second term is the charge variation term. The charge separation process is restricted to Wilson's selective ion capture process which takes into account the penetration effect. Thus, the formulation of this process is adopted the one which is suggested by Asuma and Kikuchi (1987). Other charging processes are ignored. The third term is the eddy diffusion term and $K$ is assumed as $1 \mathrm{~m}^{2} / \mathrm{s}$. Further, it is assumed that snowflakes have no charges in the initial conditions.

2-3. Ions

Ignoring large ions, the budget equation of ions is denoted as follows;

$$
\frac{\partial}{\partial t} \mathrm{n}_{1,2}=-\nabla\left(\mu_{1}, 2 \vec{E} n_{1}, 2\right)+q-\alpha n_{1} n_{2}-\frac{\delta}{\delta t} n_{1}, 2+\nabla\left(k \nabla n_{1}, 2\right),
$$

where $\mathrm{n}_{1}, 2, \mu_{1}, 2, \overrightarrow{\mathrm{E}}, \mathrm{q}, \alpha$ and $\mathrm{k}$ are the ion concentration, mobility of ion, atmospheric electric field, ionization rate function, recombination coefficient and eddy diffusion of ions, respectively. The subscript denotes that 1 indicates positive ions and 2 indicates negative ions. The first term in the right hand side in Eq. (2) is the advection term. Although the mobility of ions is widely distributed, typical values for positive and negative ions are used, that is to say, $\mu_{1}=1.4 \times 10^{-4} \mathrm{~m}^{2} / \mathrm{Vs}$ and $\mu_{2}=-1.75 \times 10^{-4}$ $\mathrm{m}^{2} / \mathrm{Vs}$. The second term is the ionization term of the air. $q$ depends on the height and is quoted by $q=\left(7.0+200 \tanh \left(0.07 \times \mathrm{z}^{-3 / 4}\right)\right) \times 10^{6} / \mathrm{m}^{3} \mathrm{~s}$ (Hoppel, 1969). The third term is the dissipation term by the recombination, and $\alpha=1.6 \times 10^{-12} \mathrm{~m}^{3} / \mathrm{s}$ is adopted. The fourth term is the removal by precipitation particles. And the last term is the eddy diffusion term and $\mathrm{K}$ is assumed to be $1 \mathrm{~m}^{2} / \mathrm{s}$.

When the electric potential gradient on the ground surface becomes strong and it exceeds a threshold value of the corona discharge current, the corona 
discharge current (point discharge current) takes place and the abundance of ions are supplied into the atmosphere from the upward point ends of tall trees and projections of artificial structures on the ground surface. The formulation of the corona discharge current suggested by Standler and winn (1979) is used. The corona current density $j$ is as follows;

and

$$
j=C E\left(|E|-E_{0}\right)^{2} \text {, if }|E|>E_{0} \text {, }
$$

$$
j=0 \text {, }
$$$$
\text { if }|\mathrm{E}|<\mathrm{E}_{0} \text {, }
$$

where $C$ is $2 \times 10^{-20} \mathrm{Am} / \mathrm{V}^{3}$ and $E_{0}$ is $5 \mathrm{kV} / \mathrm{m}$. Ions due to the corona discharge are supplied in the form of flux into the lowest grid on the ground surface.

For the initial condition, $\mathrm{n}_{1}, 2$ is set to be $\sqrt{q / \alpha}$ at $t=0$.

2-4. The electric field

The electric potential $\phi$ is determined by the Poisson's equation.

$$
\nabla^{2} \phi=-\frac{\rho}{\varepsilon_{0}},
$$

where $\rho$ is the net space charge density due to ions and precipitation particles and $\varepsilon_{0}$ is the permittivity. The electric field, therefore, is denoted as
$\vec{E}=-\nabla \phi$.

As Eq. (4) is the second order differential equation, it needs two boundary conditions. One is the electric potential on the ground surface and the top surface of the building, and they are assumed to be $0 \mathrm{~V}$. The second is the electric field at the upper boundary. We assume that the horizontal component of the electric field is zero and the vertical one is a sinusoidal change with $10 \mathrm{kV} / \mathrm{m}$ in amplitude and 20 minutes ( 1200 seconds) in period, thus $\mathrm{E}_{z}=-10000 \sin (2 \pi t / 1200) \mathrm{V} / \mathrm{m}$, where $\mathrm{t}$ is the $t$ ime in seconds.

\section{2-5. Calculation techniques}

Using the cylindrical coordinate, the relations mentioned above are rewritten in finite-differential equations by means of the forward differential method for time dependent terms, the upwind differential method for advection terms and the centrifugal differential method for other terms.

The calculation domain is $100 \mathrm{~m}$ in radial direction and $200 \mathrm{~m}$ in vertical direction. The building is assumed to be $10 \mathrm{~m}$ in radius and $22 \mathrm{~m}$ in height and it is placed at the center of the cylindrical coordinate. The horizontal space difference $(\Delta r)$ is adopted as $1 \mathrm{~m}$ and the vertical space difference $(\Delta z)$ is adopted as $2 \mathrm{~m}$. The time step $(\Delta t)$ is $0.1 \mathrm{~s}$. And the electric field is calculated with $0.5 \mathrm{~s}$ intervals. For the boundary conditions, the gradient of dependent variables (i.e., $Q_{i}, \mathrm{n}_{1}, 2$ and $\phi$ ) of the normal direction of the boundary is assumed to be zero.

\section{Results}

3-1. Distortion of the electric field surrounding the building

Figure 1 shows the distortion of the electric field near the building. In the figure, the ordinate and abscissa shows the height and radial distance in meters, respectively. The vertical electric field is given as 10 $\mathrm{kV} / \mathrm{m}$ at the upper boundary (200 $\mathrm{m}$ in height) and the space charges due to ions and precipitation particles are neglected. Figure l(a) shows the electric field with arrows and Fig. I(b) shows the magnifying power of the electric field. As the electric potentials at the building surface and the ground surface are assumed to be zero as the boundary condition of Eq. (3), the electric equipotential surfaces are crowded just above the building, especially near the corner of the building and they are sparse at the side in 


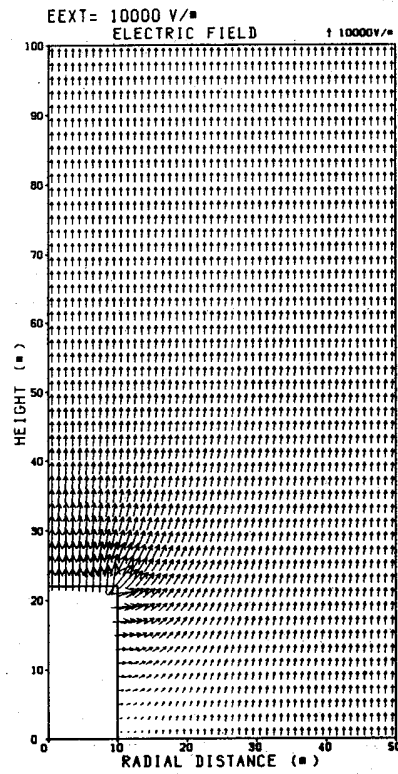

(a)

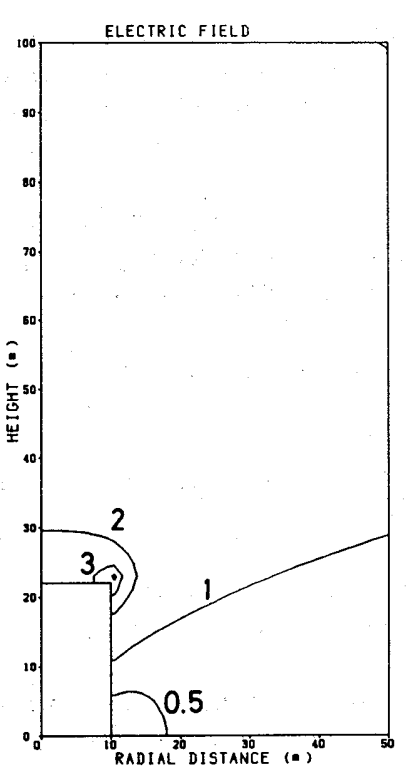

(b)
Fig. 1. Distortion of the electric field near the building. the lower parts of the building. Therefore, the electric field is intensified just above the building and it is weakened at the side on the lower part of the building. The electric field is intensified from 2.5 to 4 times on the roof of the building, especially near the corner and it is weakened less than one half at the side in the lower part of the building.

$3-2$. Variations of the atmospheric electrical elements accompanied with the sinusoidal variation of the electric field

Postulating that the electric field at the upper boundary is varied with a sine function of $10 \mathrm{kV} / \mathrm{m}$ in amplitued and 20 minutes (1200 seconds)

in period, various atmospheric elements near the building were numerically examined: In order to compare the records of the tethered balloon observation reported by Asuma et al. (1988), the time variations on the ground, at $50 \mathrm{~m}, 100 \mathrm{~m}, 150 \mathrm{~m}$ and $200 \mathrm{~m}$ in height and $10 \mathrm{~m}$ apart from the building, (therefore at $20 \mathrm{~m}$ apart from the axis of the abscissa) and on the roof (22 $\mathrm{m}$ in height) at $5 \mathrm{~m}$ apart from the axis of the abscissa as the representation of the roof are shown in Fig. 2. Figure 2 (a). shows the vertical components of the electric potential gradient (thick line) and the precipitation current density (thin line). The precipitation current density is obtained by multiplying the charges on the precipitation particles, number density of precipitation particles and their fall speed. The mirror image relation is recognized on the ground, on the roof $(22 \mathrm{~m})$ and at $50 \mathrm{~m}$ above the ground surface in the figure. Figure $2(b)$ shows the positive ion concentration (thick line) and the negative ion concentration (thin line). The variations of the vertical electric potential gradient above $50 \mathrm{~m}$ in height show the undistorted sinusoidal variations. It indicates that the space charges due to ions and precipitation particles are not strong enough to distort the electric field above $50 \mathrm{~m}$ in height. In spite of the fact that the electric potential gradient is twice or three times intensified on the roof, it reaches the upper most limit at about $10 \mathrm{kV} / \mathrm{m}$. This indicates that space charges are in existence over the roof $(22 \mathrm{~m}$ in height). When the electric potential gradient on the roof exceeds $5 \mathrm{kV} / \mathrm{m}$, the corona discharge takes place according to Eq. (3) and a large number of ions is emitted into the atmosphere. The electric potential gradient on the ground also reaches the upper most limit at approximately $2 \mathrm{kV} / \mathrm{m}$. When the electric potential gradient on the roof is less 


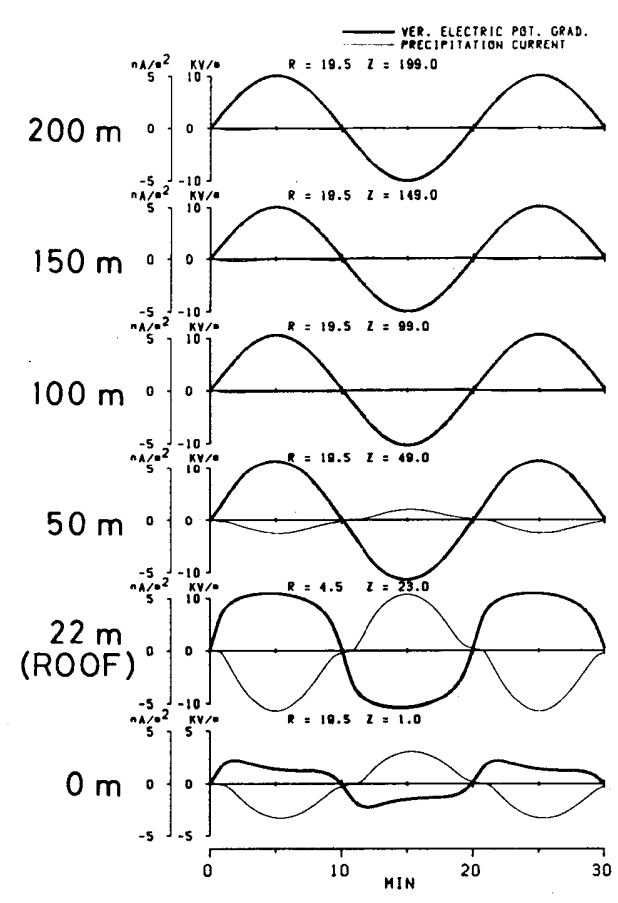

(a)

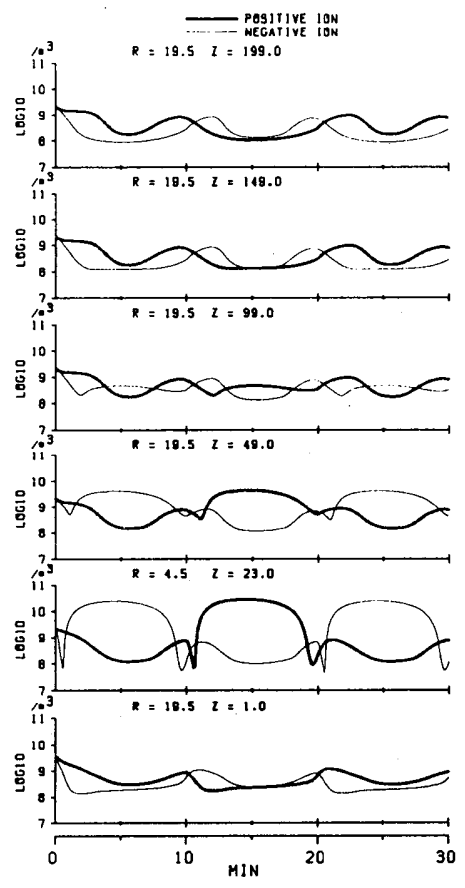

(b)

Fig, 2. Time variations of the atmospheric electrical elements.

(a) Electric potential gradient and precipitation current density,

(b) Positive and negative ion concentrations.

than $5 \mathrm{kV} / \mathrm{m}$, and the corona discharge does not occur, the electric potential gradient on the ground varies in a similar manner to that on the roof. But when the corona discharge takes place on the roof, the electric potential gradient on the ground decreases in contrast to the fact that the potential gradients at other altitudes increase. As to the precipitation current, it is stronger on the roof than that at other altitudes. On the ground surface, on the other hand, it appears to be about one half of the magnitude on the roof. As the electric potential gradient on the ground surface is about onefifth of that on the roof, the ratio of the precipitation current to the electric potential gradient on the ground is larger than that on the roof. The precipitation particles above $100 \mathrm{~m}$ in height are scarcely electrified. It is recognized that ions which are emitted from the roof move upward and they reach $100 \mathrm{~m}$ in height.

Vertical structures of the atmospheric electrical elements are shown in Fig. 3 at $300 \mathrm{~s}$ and in Fig. 4 at $900 \mathrm{~s}$, where the magnitude of the electric field at the upper boundary indicates at its maximum value. Figures 3 and 4 show the electric field (a), space charge density due to ions (b) and space charge density due to precipitation particles (c), respectively. As the electric field is intensified on the roof of the building; a large number of ions is emitted by the corona discharge from the roof of the building into the atmosphere. However, the ions do not arrive at high altitude and most of ions exist below the $40 \mathrm{~m}$ level. On the other hand, the precipitation charges are rapidly electrified below the $60 \mathrm{~m}$ in height. Therefore, the 


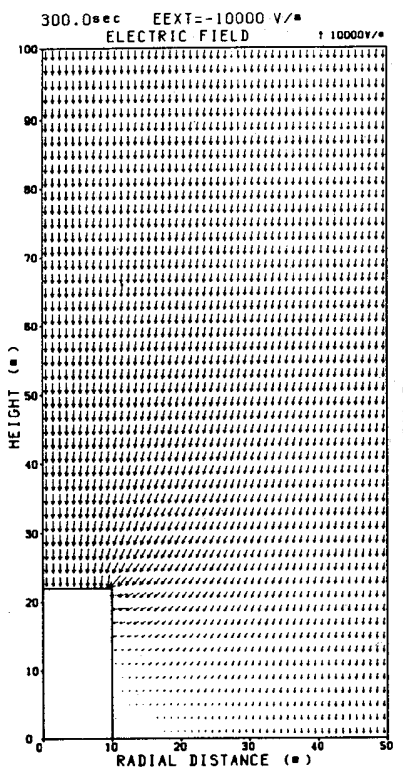

(a)

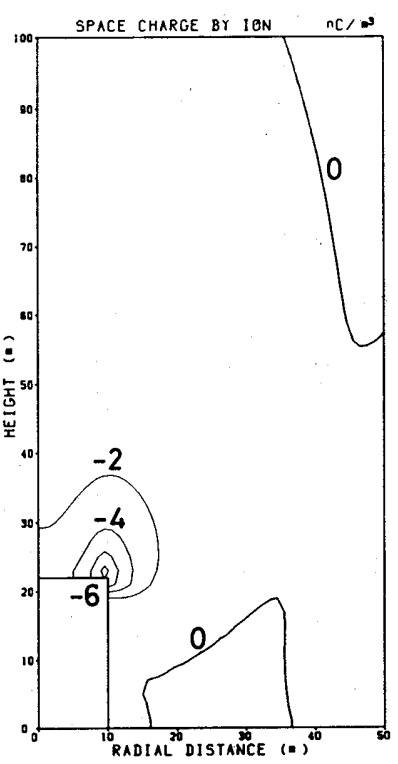

(b)

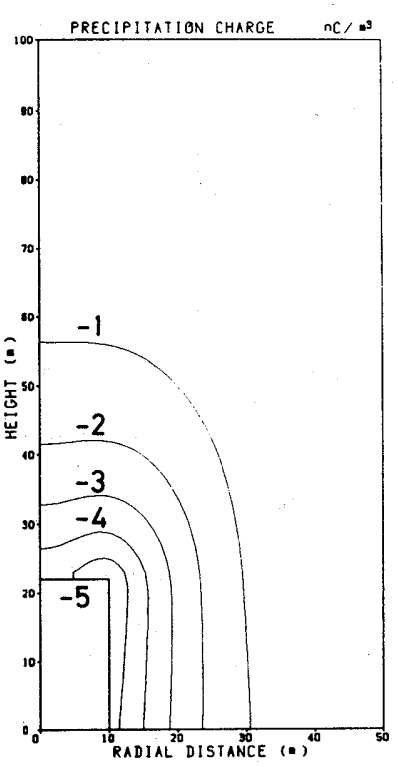

(c)

Fig. 3. Vertical stmuctures of the atmospheric electrical elements near the building at $300 \mathrm{~s}$. (a) Electric field, (b) Space charge density due to ions. (c) space charge density due to precipitation particles.

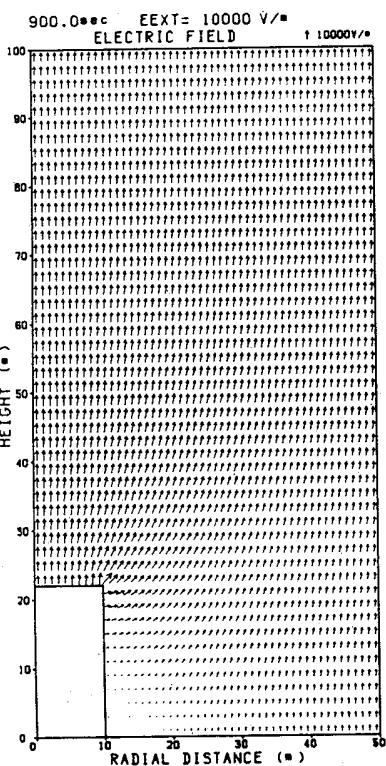

(a)

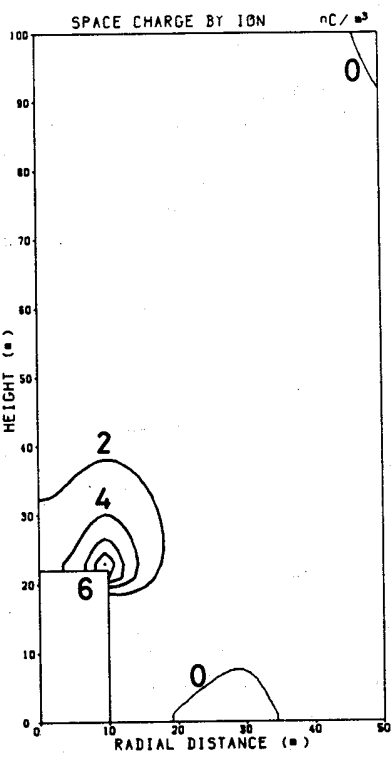

(b)

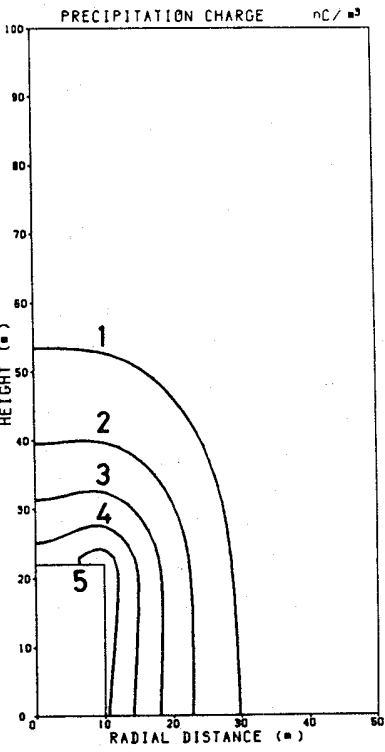

(c)

Fig. 4. As in Fig. 3 but at $900 \mathrm{~s}$. 
ions which are emitted from the roof are immediately captured by snow particles and descend back to the ground. It is very noticeable that precipitation particles observed on the ground beside the building are already electrified at the height of the top of the building and they fall to the ground surface. Thus, although the electric field is weakened on the ground beside the building, the amount of charges on individual precipitation particles is rather large. This phenomenon is consistent with the observational results obtained by Asuma et al. (1988).

The relation between the radius of precipitation particles and their charge density at $300 \mathrm{~s}$ and $900 \mathrm{~s}$ is shown in Fig. 5. Figure 5(a) shows the results on the ground and Fig. 5 (b) shows that on the roof. Precipitation particles are charged negatively at $300 \mathrm{~s}$, on the other hand, they are charged positively at $900 \mathrm{~s}$ over the entire range of the radius examined. The distribution of the space charges due to precipitation particles and their radius is almost the same between $300 \mathrm{~s}$ and $900 \mathrm{~s}$. And the charges on precipitation particles are about twice on the roof than those on the ground. The most effective size for the contribution of the snow particles to the total precipitation charge density seems to be $3-4 \mathrm{~mm}$ in radius on the ground and on the roof.

\section{Concluding remarks}

The structures of the atmospheric electrical elements during snowfalls near the building were examined by means of the two dimensional numerical experiments which take into account the cylindrical building with a size of $10 \mathrm{~m}$ in radius and $22 \mathrm{~m}$ in height. Wilson's ion capture process and supplement of ions due to the corona discharge at the bottom grids were considered as the charging mechanism. As the electric field on the roof of the building is intensified, the corona discharge is liable to occur there and a great number of ions is emitted from the roof into the atmosphere. The ions move upward owing to the electric force but they can not reach very high altitude. Therefore, the highest concentration of ions appear below a $40 \mathrm{~m}$ level. On the other hand, the precipitation particles are rapidly electrified below the 60 $m$ level. Therefore, the ions emitted from the roof of the building are rapidly captured by snow particles and charged snow particles descend to the ground.

These calculation results were qualitatively

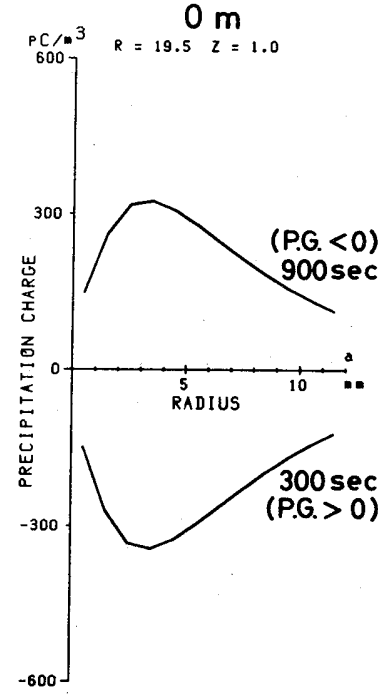

(a)

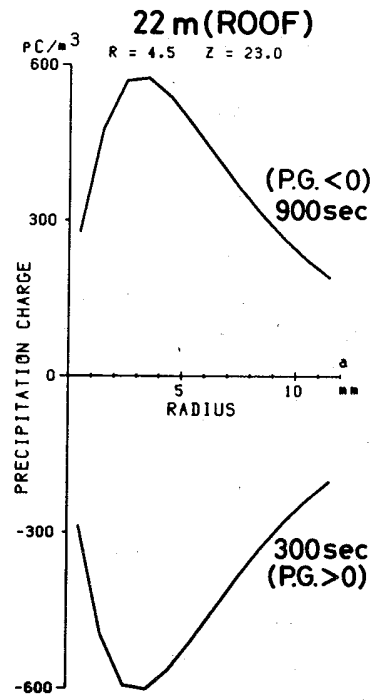

(b)

Fig. 5. Relation between the radius of precipitation particles and their charge density at $300 \mathrm{~s}$ and $900 \mathrm{~s}$. (a) on the ground surface. (b) on the roof. 
in agreement with the results of the observation done by Asuma et al. (1988) by means of the tethered balloon. They concluded that the snowflakes were weakly electrified and the mirror image relation was not always observed at $100 \mathrm{~m}$ or $200 \mathrm{~m}$ aloft. On the other hand, the snowflakes were strongly electrified and the mirror image relation was clearly observed near the ground surface. Further, the electric potential gradient (the electric field) was weakened on the ground beside the building. The discrepancy of the variations of the electric potential gradient between the roof and on the ground was conspicuous during the corona discharge which took place on the roof. And further, in spite of the fact that the potential gradient was weak, snow particles were strongly charged on the ground. These phenomena were confirmed by the numerical experiments.

Acknowledgments. A part of this research was supported by Grant-in-Aid for the encouragement of Young Scientists No. 61790129 (Y.A.), of the Ministry of Education, Science and Culture of Japan. Calculations were carried out using a HITACHI M-200H of Center for Information Processing Education, Hokkaido University.

\section{References}

Asuma, Y. and K. Kikuchi, Experiments of the charging mechanism of ice particles by the ion-capture process, J. Fac. Sci., Hokkaido Univ., Ser. 7 (Geophys.) , 7, 239-250, 1983 .

Asuma, Y. and K. Kikuchi, Numerical experiments of the charging mechanism of precipitation particles by the ion-capture process below the cloud, J. Meteor. Soc., Japan, 65, 973-989, 1987.

Asuma, Y., K. Kikuchi, T. Taniguchi and S. Fujii, Vertical structures of the atmospheric electrical potential gradient and behavior of the precipitation charges during snowfalls near the ground surface, J. Meteor. Soc., Japan, 66, 1988. (now printing)

Chalmers, J. A., The origin of the electric charge on rain, Quart. J. Roy. Meteor. Soc., 77, 249-259, 1951.

Gunn, K. L. S. and J. S. Marshall, The distribution with size of aggregate snowflakes, J. Meteor., 15, 452-461, 1958.

Hoppel, W. A., Planetary Electrodynamics, Vol. 2, edited by S. C. Coroniti and J. Hughes, Gordon and Breach Science Publishers, New York, 503 pp., 1969.

Kikuchi, K., Atmospheric electrical properties of snow clouds with precipitation, J. Meteor. Soc., Japan, 53, 322-333, 1975.

Kikuchi, K., H. Uyeda, T. Takahashi and K. Inatsu, Atmospheric electrical observations of precipitation particles in the winter monsoon at the Hokuriku district, Japan, J. Fac. Sci., Hokkaido Univ., Ser. 7 (Geophys.), $6,31-48,1979$.

Locatelli, J. D. and P. V. Hobbs, Fall speeds and masses of solid precipitation particles, J. Geophys, Res., 79, 2185-2197, 1974.

Magono, C. and K. Orikasa, on the disturbance of surface electric field cause by snowfall, J. Meteor. Soc., Japan, 44, 260-279, 1966.

Ogawa, T., Electricity in rain, J. Geomagn. Geoelect. 12, 21-31, 1960.

Smith, L. G., The electric charge on raindrops, Quart. J. Roy. Meteor. Soc., $81,23-47,1955$.

Standler, R. B. and W. P. Winn, Effects of coronae on electric fields beneath thunderstorms, Quart. J. Roy. Meteor. Soc., 105, 285-302, 1979. 